\title{
Complement System as a Target for Therapies to Control Liver Regeneration/Damage in Acute Liver Failure Induced by Viral Hepatitis
}

\author{
Juliana Gil Melgaço ${ }^{D},{ }^{1}$ Carlos Eduardo Veloso, ${ }^{2}$ Lúcio Filgueiras Pacheco-Moreira, ${ }^{3}$ \\ Claudia Lamarca Vitral, ${ }^{4}$ and Marcelo Alves Pinto $\mathbb{1}^{1}$ \\ ${ }^{1}$ Laboratório de Desenvolvimento Tecnológico em Virologia, Instituto Oswaldo Cruz, Fundação Oswaldo Cruz, Rio de Janeiro, Brazil \\ ${ }^{2}$ Departamento de Patologia, Instituto Nacional do Câncer, Rio de Janeiro, Brazil \\ ${ }^{3}$ Hospital Federal de Bonsucesso, Rio de Janeiro, Brazil \\ ${ }^{4}$ Departamento de Microbiologia e Parasitologia, Instituto Biomédico, Universidade Federal Fluminense, Niterói, Brazil
}

Correspondence should be addressed to Juliana Gil Melgaço; juliana.melgaco@gmail.com

and Marcelo Alves Pinto; marcelop@ioc.fiocruz.br

Received 12 May 2018; Accepted 28 August 2018; Published 8 October 2018

Academic Editor: Dechun Feng

Copyright ( 2018 Juliana Gil Melgaço et al. This is an open access article distributed under the Creative Commons Attribution License, which permits unrestricted use, distribution, and reproduction in any medium, provided the original work is properly cited.

\begin{abstract}
The complement system plays an important role in innate immunity inducing liver diseases as well as signaling immune cell activation in local inflammation regulating immunomodulatory effects such as liver damage and/or liver regeneration. Our aim is to evaluate the role of complement components in acute liver failure (ALF) caused by viral hepatitis, involving virus-induced ALF in human subjects using peripheral blood, samples of liver tissues, and ex vivo assays. Our findings displayed low levels of $\mathrm{C} 3 \mathrm{a}$ in plasma samples with high frequency of $\mathrm{C} 3 \mathrm{a}, \mathrm{C} 5 \mathrm{a}$, and $\mathrm{C} 5 \mathrm{~b} / 9$ deposition in liver parenchyma. Meanwhile, laboratory assays using HepG2 (hepatocyte cell line) showed susceptibility to plasma samples from ALF patients impairing in vitro cell proliferation and an increase in apoptotic events submitting plasma samples to heat inactivation. In summary, our data suggest that the complement system may be involved in liver dysfunction in viral-induced acute liver failure cases using ex vivo assays. In extension to our findings, we provide insights into future studies using animal models for viral-induced ALF, as well as other associated soluble components, which need further investigation.
\end{abstract}

\section{Introduction}

Acute liver failure (ALF) is a complex and rare clinical syndrome characterized by the development of severe liver dysfunction, promoted by extensive death of functional cells. The mortality rate is close to $80 \%$, and liver transplantation [1-4] is the only treatment modality available to this date. ALF can be induced by viral infections and toxicity promoted by drug abuse or alcoholism. In Brazil, viral infections are responsible for the majority of ALF cases, including viral hepatitis viruses such as hepatitis A virus (HAV) and hepatitis B virus (HBV), as well as coinfections related to hepatitis $\mathrm{C}$ virus (HCV), HIV, Epstein-Barr virus, and CMV [5-7].
Inflammatory response is strongly associated with liver diseases, and activation can trigger liver damage with aggressive hepatocyte loss [8]. In ALF, extensive liver injury can be caused by a variety of molecules of the innate immune system, and the complement system plays an important role in this process $[9,10]$. The complement system is the major component of innate immunity; its protective function starts with a cascade of proteases and soluble factors that activates the immune system, stimulating microbial clearance [11]. Nevertheless, the function of the complement system is associated with processes of development, degeneration, and regeneration of multiple organs [12-14]. Anaphylatoxins $\mathrm{C} 3 \mathrm{a}$ and $\mathrm{C} 5 \mathrm{a}$ present potential chemoattractant activity to amplify immune cell recruitment such as macrophages 
TABLE 1: Characteristics of the study population.

\begin{tabular}{lcccccccccc}
\hline Subjects & Samples & Age & Gender & ALT & AST & INR & Encephalopathy & Outcome & Diagnostic & Etiology \\
\hline 1 & HS1 & 29 & F & 14 & 21 & 1 & None & NA & Healthy & None \\
2 & HS2 & 27 & M & 16 & 22 & 1 & None & NA & Healthy \\
3 & HS3 & 29 & F & 13 & 19 & 1.1 & None & NA & Healthy \\
4 & HS4 & 26 & M & 23 & 33 & 0.9 & None & NA & Healthy & None \\
5 & HS5 & 46 & F & 18 & 26 & 0.8 & None & NA & Healthy \\
6 & HS6 & 31 & F & 11 & 15 & 0.9 & None & NA & Healthy & None \\
7 & HS9 & 26 & F & 16 & 25 & 0.9 & None & NA & Healthy \\
8 & HS10 & 33 & F & 13 & 18 & 1.1 & None & NA & Healthy \\
9 & ALF1 & 5 & F & 326 & 331 & 6.7 & IV & Survival & Acute liver failure & HAV \\
10 & ALF2 & 14 & M & 877 & 1790 & 4.32 & IV & Death & Acute liver failure & HAV \\
11 & ALF3 & 7 & M & 1562 & 5611 & 2.55 & III & Death & Acute liver failure & HAV \\
12 & ALF4 & 14 & M & 313 & 330 & 8.64 & IV & Death & Acute liver failure & HAV \\
13 & ALF5 & 1 & F & 668 & 171 & 6.38 & II & Death & Acute liver failure & HAV \\
14 & ALF6 & 24 & M & 964 & 762 & 3.3 & II & Death & Acute liver failure & HBV \\
15 & ALF7 & 31 & F & 314 & 562 & 2.1 & II & Survival & Acute liver failure & HBV \\
16 & ALF8 & 17 & M & 200 & 120 & 1.7 & II & Survival & Acute liver failure & HAV \\
\hline
\end{tabular}

Legend: HS: healthy subjects; ALF: acute liver failure patients; HAV: hepatitis A virus; HBV: hepatitis B virus; F: female; M: male; NA: not applicable.

and neutrophils into the liver parenchyma [15]; quickly, C5a is converted to C5aDesArg in vivo, leading to local inflammation [16]. Following the complement cascade, C5b with C6-C9 forms the "membrane attack complex" (MAC), capable of lysing infected cells and pathogens [17, 18].

A susceptible cell culture system and animal models are important to improve knowledge of viral liver pathogenesis and promising therapies. However, useful viral-induced ALF animal models are not simple; in addition, the diversity of liver cell lines is used to study therapy interventions and also to understand mechanisms related to liver diseases, such as viral hepatitis $[19,20]$. Here, we assessed the toxicological effects of the complement system in the peripheral blood of patients during acute liver failure.

\section{Materials and Methods}

2.1. Study Population and Samples. Blood samples $(n=8)$ and liver samples $(n=6)$ from ALF patients and blood samples $(n=10)$ and liver samples $(n=1)$ from healthy subjects (HS) were collected at the Liver Clinic/Hospital Federal de Bonsucesso, Rio de Janeiro, Brazil, between February 2004 and November 2013.

Inclusion criteria included the presence of coagulopathy (INR $\geq 1.5$ ) and encephalopathy score above II, according to O'Grady et al. [21] and as described previously [7, 22, 23]. Clinical details of the study population are shown in Table 1.

Screening to investigate the etiological agent involved in ALF cases as well as in samples of healthy donors was performed for HAV, HBV, and HCV detection and also for other infectious and autoimmune disorders as described by Melgaço et al. [7].

The adopted protocol performed complied with relevant laws and institutional guidelines according to the ethical standards of the Declaration of Helsinki approved by the Institutional Review Board of Fiocruz (\#222/03).

\subsection{Laboratory Assays}

2.2.1. Detection of C3a Levels in Peripheral Blood Circulation. Blood samples $(9 \mathrm{~mL})$ were centrifuged $(200 \times g / 10 \mathrm{~min})$ to separate plasma from other products. Plasma samples were aliquoted and stored at $-70^{\circ} \mathrm{C}$ until laboratory assays. Initially, plasma samples were divided into two groups: in the first one, plasma was thawed at room temperature (RT) overnight and in the second one, plasma was thawed at RT overnight and submitted to temperature complement inactivation by heating at $57^{\circ} \mathrm{C}$ for $30 \mathrm{~min}$. To detect C3a levels in plasma samples, a commercial kit was used according to the manufacturer's instructions (eBioscience, cat \#BMS2089TEN, San Diego, CA, USA).

2.2.2. Detection of Anaphylatoxins and Membrane Attack Complex (MAC) in Liver Tissue Samples. Liver samples were obtained at the time of transplantation and stored in liquid nitrogen until immunofluorescence assays, sectioned at $5 \mu \mathrm{m}$, and stained with antibodies to membrane attack complex C5b/9 (clone: aE11, Santa Cruz cat \#SC-58935, Brazil); the C3a component (clone: K13/16, Santa Cruz cat \#SC-47688, Brazil) and C5a component (clone: 2952, Santa Cruz cat \#SC-52634, Brazil) were applied to the sections at a dilution of $1: 50$ for 1 hour at $37^{\circ} \mathrm{C}$. After incubation, sections were washed in phosphate-buffered saline $(\mathrm{pH}=7.2)$ and incubated with the secondary antibody Alexia Fluor $488^{\circledR}$ (Abcam cat \#AB-150113, USA) at a dilution of $1: 1000$. Photomicrographs were taken in a confocal microscope FV10i-O (Olympus, Japan) using FV10-ASW software. Calculation of marked areas was carried out using the software ImageJ (https://imagej.net/ImageJ).

2.2.3. In Vitro Evaluation of ALF Soluble Components. Hepatocellular carcinoma lineage (HepG2, ATCC ${ }^{\circledR}$ number: HB- $8065^{\mathrm{TM}}$ ) was chosen to evaluate ex vivo effects of ALF 
soluble components from plasma samples, since they are a well-established model for hepatocyte metabolism that under specific culture conditions maintains normal cell functions $[24,25]$. HepG2 cultures were maintained in RPMI1640 (pH 7.4) (Gibco, USA) supplemented with 10\% fetal bovine serum (FBS) (Gibco, USA) and $2 \mathrm{mM} \mathrm{L-glutamine} \mathrm{(Merck,}$ Germany) in $75 \mathrm{~cm}^{2}$ bottles at $37^{\circ} \mathrm{C}$ in a $\mathrm{CO}_{2}$ humidified incubator. The medium was changed twice weekly, and passages were performed using trypsinization solution (0.2\% and $0.02 \%$ versene in RPMI1640 medium). HepG2 confluency was regularly checked. The plasma of healthy subjects and ALF plasma samples were added to HepG2 cultures to assess the hypothesis of their toxicological effects. HepG2 cultures in a confluent monolayer were kept for 24 hours at $37^{\circ} \mathrm{C}$ in 24 -well plates $\left(5 \times 10^{4}\right.$ cells/well $)$. Then, different concentrations of plasma samples (complement heat-inactivated and noninactivated) diluted in RPMI1640 $(0.1 \%, 1 \%$, and $10 \%)$ were added to HepG2 cultures and incubated for 48 hours. Then, to assess viability, HepG2 cultures were labeled using $5 \mu \mathrm{M}$ of fluorescent vital dye cell trace in RPMI1640 (CFSE-FITC, Invitrogen ${ }^{\circledR}$, USA). Negative proliferation percentage using CFSE-FITC was quantified by flow cytometry. Positive control of the absence of cell proliferation was carried out using colchicine at $10 \mu \mathrm{M}$ [26]. Negative control was performed adding RPMI1640 with $10 \%$ fetal bovine serum (FBS) heat-inactivated $\left(57^{\circ} \mathrm{C}, 30 \mathrm{~min}\right)$ in HepG2 culture.

Levels of liver enzymes (ALT and AST) in supernatant of cell cultures were quantified to assess cellular damage and apoptosis caused by ALF plasma samples (Diasys ${ }^{\circledR}$, Germany); HAV and HBV viral load quantification was performed by real-time PCR $[27,28]$. HepG2 cells were incubated with $\alpha$-CD95-FITC (annexin V, clone DX2, BD Pharmingen, USA). In this assay, HepG2 cells were also kept for $48 \mathrm{~h}$, and positive control was assessed using ascorbic acid (AA) $(70 \mu \mathrm{M})$ for a $48 \mathrm{~h}$ incubation [29]. Blockage of membrane pores was achieved using specific phosphate saline solution (5\% of $0.1 \mathrm{M} \mathrm{BSA}$ ) and not fixed, according to the previous description [30].

After incubation, cells were analyzed by flow cytometry in both assays, 20,000 live cells were analyzed using a FACSCalibur $^{\mathrm{TM}}$ flow cytometer with four fluorescence channels (FL1-530/30, FL2-585/42, FL3-670LP, and FL4-661/16), and off-line analysis was performed using FlowJo software (version 10.0.5) (FlowJo, LLC data analysis software, USA).

2.2.4. Statistical Analysis. Statistical analyses were performed using Kruskal-Wallis and Dunn's multiple comparison test. ${ }^{*} p \leq 0.05,{ }^{* *} p \leq 0.01$, and ${ }^{* * *} p \leq 0.001$. All statistical analyses were performed using GraphPad Prism software version 7.

\section{Results}

3.1. The Lowest C3a Levels Detected in ALF Plasma Samples. Plasma samples from ALF patients and healthy subjects were submitted to C3a detection assays. Comparatively, Figure 1 shows superior levels of C3a detected among healthy donors (both heat-inactivated and noninactivated samples) even after thermal treatment $(p=0.0419)$.

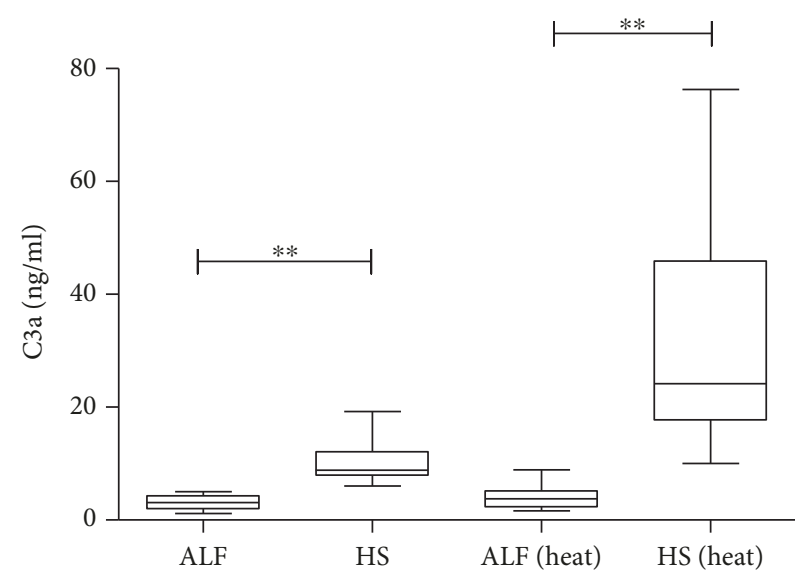

Figure 1: Soluble component C3a of complement system characterization of plasma samples from acute liver failure patients (ALF) and healthy subjects (HS) under heat inactivation (heat) and without heat inactivation.

3.2. Complement System Was Detected in Liver Samples from ALF Patients. Comparatively, a significant high percentage of C3a, C5a, and C5b/9 in labeled liver cells from ALF patients (Figure 2) was detected in tissue sections.

3.3. ALF Plasma Samples Induce Antiproliferative Activity and Apoptosis of In Vitro HepG2 Expansion. Impairment of in vitro HepG2 expansion in the presence of $10 \%$ heatinactivated (EC50, $p=0.0034)$ and noninactivated ALF plasma samples (EC50, $p=0.0153$ ) was observed despite reduced circulation of C3a in ALF patients, similar to what was detected in positive controls (colchicine) (Figure 3). Results are presented in a $10 \%$ concentration of plasma samples diluted in RPMI1640 media.

To evaluate membrane damage in HepG2 cultures, alanine and aspartate aminotransferase levels (ALT and AST) in supernatant after ALF plasma exposure were measured and no changes in AST levels were found (data not shown). ALT levels were significantly higher in heat-inactivated ALF plasma than in plasma of healthy subjects and noninactivated ALF plasma, as displayed in Figure 4(a). In addition, we also explored the viral load of hepatitis A virus (HAV) and hepatitis $B$ virus (HBV) in plasma samples used in cell cultures before and after thermal inactivation and on supernatant after ALF plasma exposure. No significant changes in viral load were found before and after thermal inactivation $(p>0.05)$, as well as after HepG2 exposure to ALF plasma samples $(p>0.05)$ (Table 2).

Subsequently, by extending our analysis to annexin $\mathrm{V}$, the median percentage of apoptotic cells expressing annexin $\mathrm{V}$ was significantly high in the presence of $10 \%$ heat- and noninactivated ALF plasma samples compared with that of HS samples (Figure 4(b)).

\section{Discussion}

The complement system activation occurs in viral liver diseases [31-35]. Despite preventive measures, some viral liver 


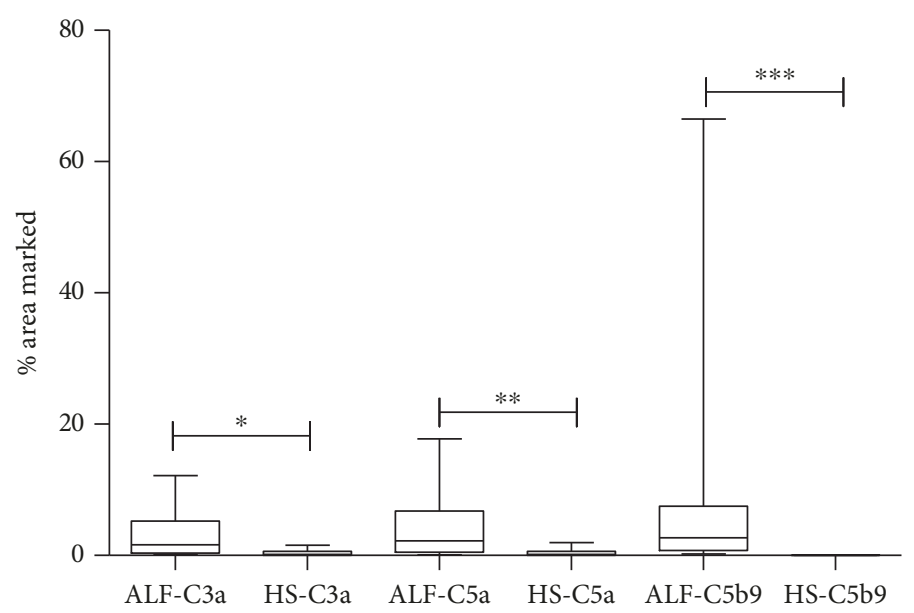

(a)

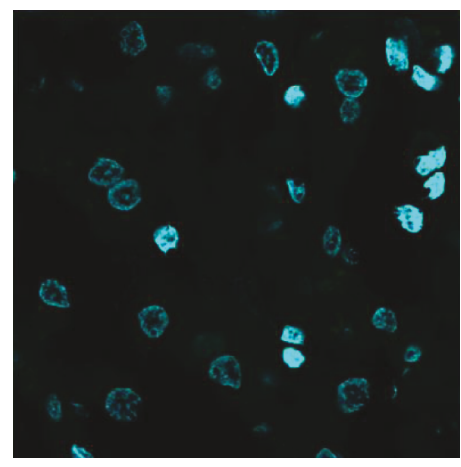

(b)

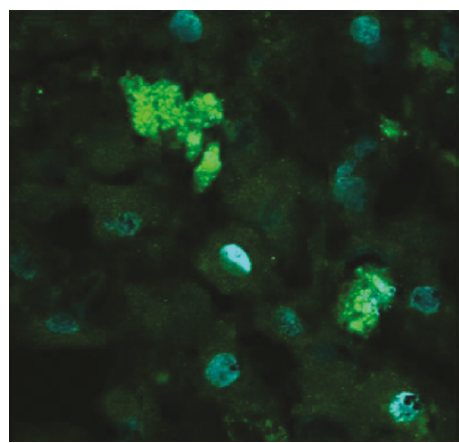

(e)

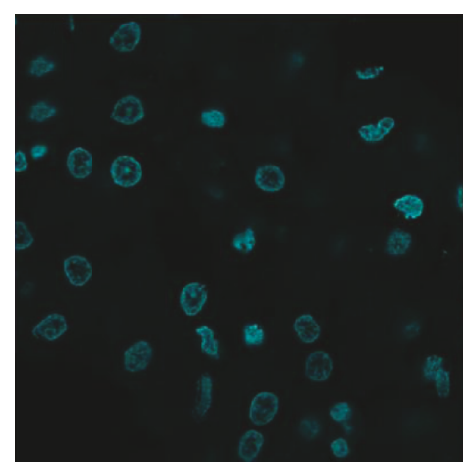

(c)

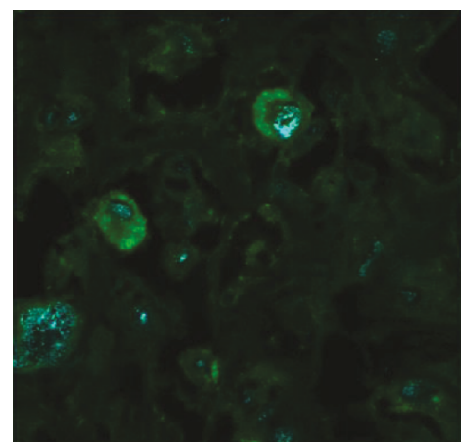

(f)

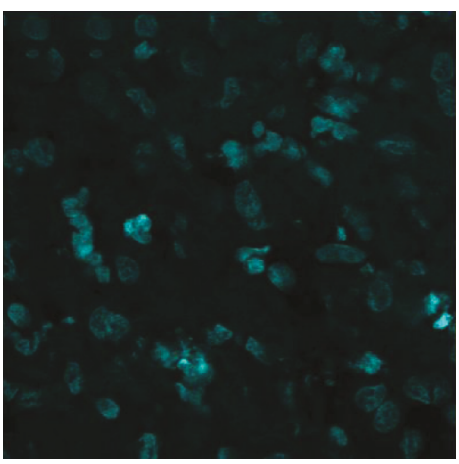

(d)

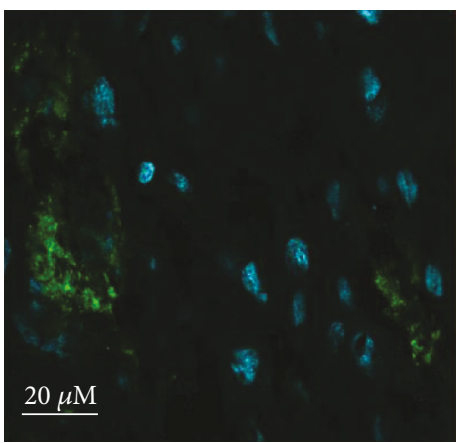

(g)

Figure 2: Liver deposit of anaphylatoxins C3a, C5a, and C5b/9 (MAC): (a) percentage of the area marked with anaphylatoxins in healthy subjects (HS) and acute liver failure (ALF) samples of liver tissue; (b-g) immunofluorescence assay (IFA) of liver samples tested for $\alpha \mathrm{C} 3 \mathrm{a}$ $(\mathrm{b}, \mathrm{e}), \alpha \mathrm{C} 5 \mathrm{a}(\mathrm{c}, \mathrm{f})$, and $\alpha \mathrm{C} 5 \mathrm{~b} / 9(\mathrm{~d}, \mathrm{~g})$; the yellow underlined figures are from healthy subjects $(\mathrm{b}, \mathrm{c}, \mathrm{d})$; the red underlined figures are from acute liver failure patients (e, f, g). Confocal microscopy zoom was of 400-fold.

diseases are widespread in developing countries causing acute hepatitis and its worst outcome is acute liver failure $[33,36]$. Here, we confirmed the early impact of ALF plasma samples on HepG2 proliferation and viability, mimicking ALF liver environment. Some studies established the effects of the complement system on liver regeneration; however, the effective involvement of the components in viral liver injury and regeneration is still unknown $[14,18]$.

Our findings displayed a striking loss of C3 levels in peripheral blood from ALF patients, followed by high deposition of complement system components, such as C3a, C5a, and C5b-9 (MAC) in the liver parenchyma (liver explant) at the time of transplantation. C3 is a major component of the complement cascade, present at the early stage of liver inflammation [37], and C3 can regulate efflux and metabolism of steroid lipids in hepatocyte proliferation $[18,38]$. In our previous report, plasmatic elevation titers of systemic inflammatory mediators (TNF- $\alpha$, IL-6, IL-8, IL-10, IFN $\gamma$, and total mtDNA) were demonstrated in ALF patients $[7,22,23,39]$. Similarly, other authors described the synergic 


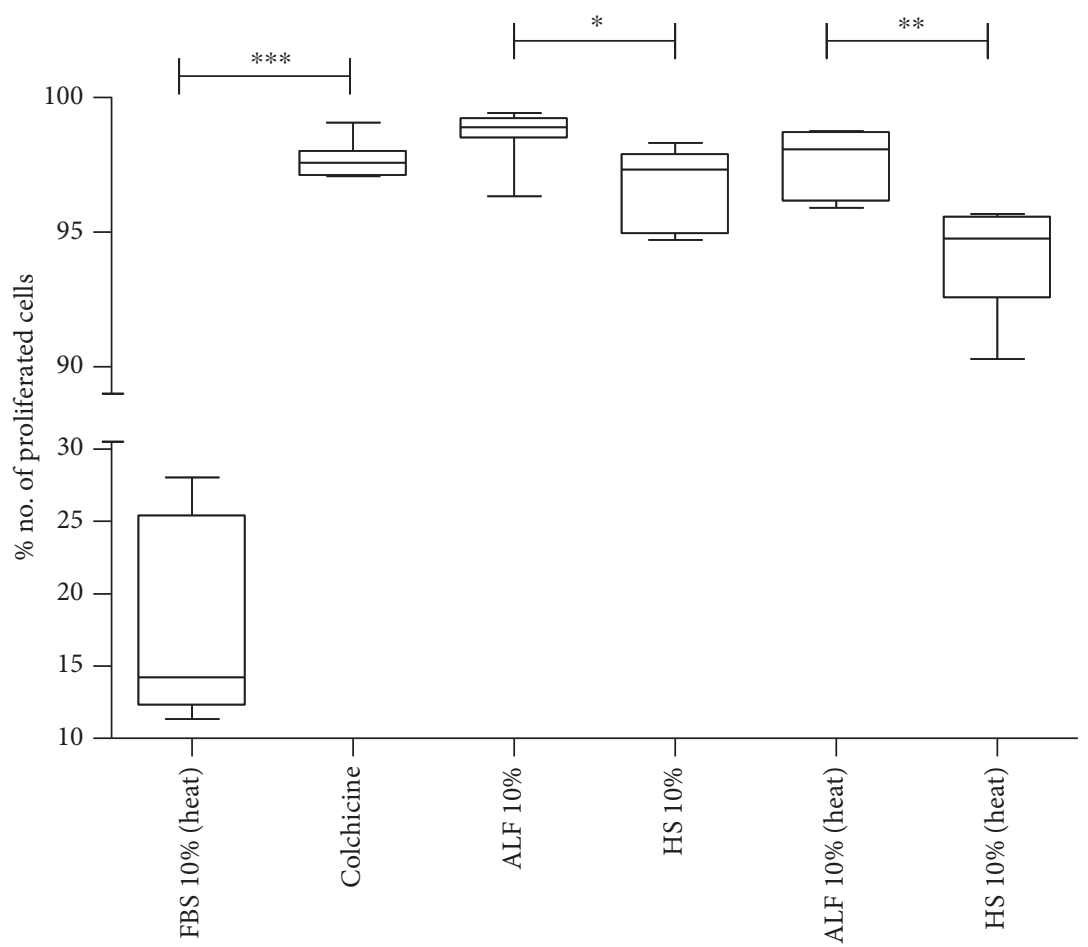

Figure 3: Effect of plasma (10\%) from acute liver failure patients (ALF) and healthy subjects (HS) on HepG2 proliferation. Abbreviations: heat: heat-inactivated; ALF $10 \%$ vs. ALF $10 \%$ (heat), $p=0.0489$.

effect of IL-1 beta and IL-6 on C3 mRNA transcription and C3 secretion in rat hepatocytes [40] since hepatocytes and Kupffer cells constitutively express receptors for C3 and C5a $[40,41]$.

In this study, viral-induced ALF patients with reduced C3a levels were associated with critical and progressive clinical conditions (donor shortage) and liver dysfunction. Similarly, nonviral etiologies [42, 43], LPS/D-GaINinduced ALF [9], and chronic hepatitis cases [44, 45] could be justified by protein aggregates mediated by vitronectin or clusterin (complement regulatory proteins) [46], limited to the measurement of the complement components [45]. Displacement of the complement system from peripheral to central compartments in viral-induced ALF patients was already described in ALF animal models $[15,18]$ which were not exactly similar between animal and human studies [47]. Additionally, this study highlights that reduced levels of C3a in plasma from viral-induced ALF patients could not stimulate division of healthy hepatocytes since C3a biosynthesis depends on the normal liver function [32] as discussed by other authors in mouse models [15]. Hepatic deposition of components found in higher percentage in ALF liver samples could also suggest attempts for liver regeneration $[18,38,48]$, which were not successful [10]. Despite the decrease in C3a levels in the plasma, its function cannot be ignored since it can trigger several cellular communications with different functionalities [13, 49]. On the other hand, lower C3a plasma levels and liver deposition can be a signal of liver "immunological storm" inducing hepatic damage $[9,32,44,45]$. Those contradictory aspects discussed here raise the need for further investigation to understand the immune system in ALF syndrome.

Surprisingly, we observed a significant increase in C3a levels when plasma samples from healthy subjects were heat-inactivated. Contradictorily, some studies demonstrated that heat may influence [50] or not [51] immunoassay results, also associated with antibodies' interaction with protein activity after heating [50-52]. In our protocol, heat inactivation was performed at $57^{\circ} \mathrm{C}$ for 30 minutes; some studies described that complete inactivation of complement components in human serum can be effective for $30-60$ minutes at $57^{\circ} \mathrm{C}[52,53]$. However, Moore and colleagues showed that $\mathrm{C} 3 \mathrm{~b}$ remained detectable and functional in decreased levels after heat inactivation of human sera [52].

Relevant weaknesses were identified in this study such as (i) soluble plasma components (endotoxin, hormones, bile acid, and other proteins); (ii) the reduced number of patients enrolled in this study related to the reduced number of liver transplants now occurring in Rio de Janeiro, Brazil; and (iii) scarce cases of ALF syndrome $(0.5-1 \%$ of acute hepatitis cases $[5,7])$.

In addition, we observed that in vitro HepG2 proliferation exposed to heat- or noninactivated plasma samples from ALF patients was significantly reduced, confirming our hypothesis related to the impairment of replicative capacity of resident hepatocytes. Intriguingly, during the early stages of liver damage, inflammatory cytokines induce healthy hepatocyte division [54]; however, during liver failure, its regenerative process is inadequate to match rapid, confluent loss of hepatocyte mass and function $[8,10]$. 


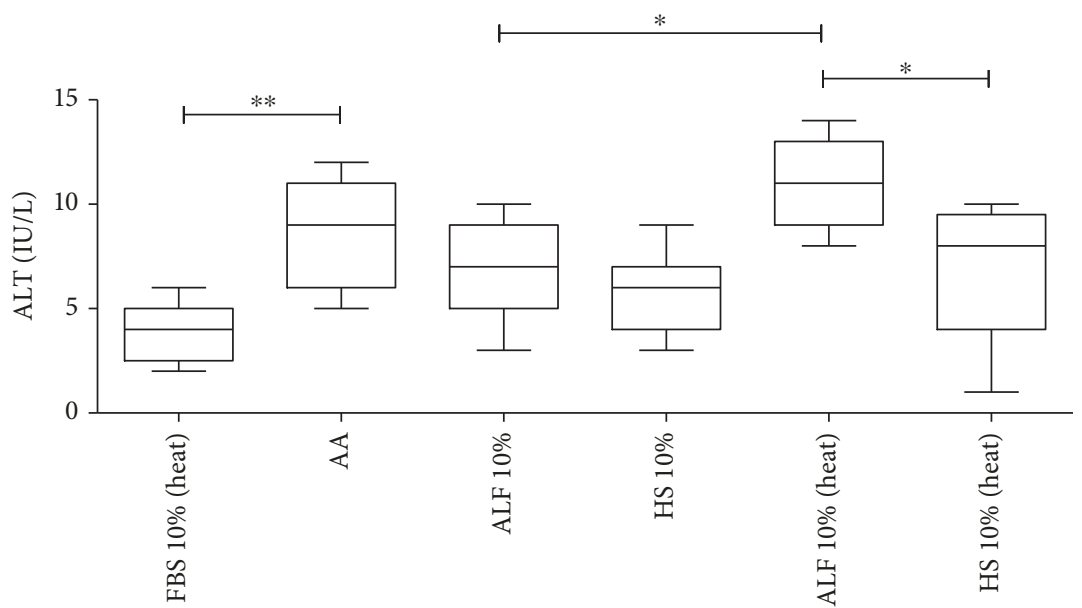

(a)
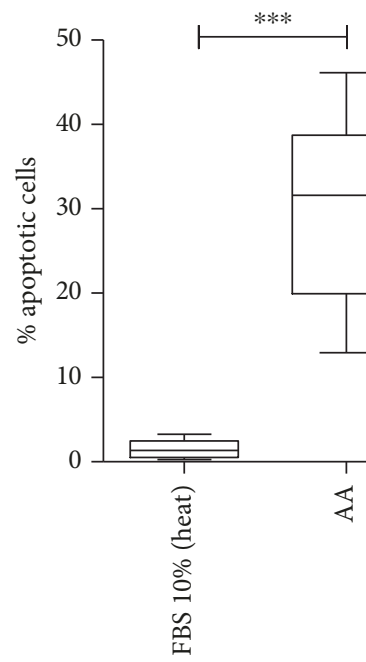
inactivation, a slight decrease in the viral load was observed (Table 2), as described by others [59]. Probably, viable particles were not present in those samples, since plasma samples with no more than $4 \log _{10}$ copies $/ \mathrm{mL}$ were selected for this study, and HepG2 cell lines were not susceptible to HBV or HAV replication [60-62].

Our results raise the possibility of $\mathrm{C} 3$ as a target for new therapeutic approaches based on C3 function in hepatocytes for liver regeneration attempts. Although we cannot predict possible influence efficacy in this type of therapy, the knowledge of C3 effects on immortalized human hepatocyte cell lines could be useful to assess hepatocyte regeneration. It is noteworthy that other components (phosphate, creatinine, bile acid, and reactive oxygen species, among others) need further investigation since soluble factors are associated with fulminant hepatitis outcome [63-66]. However, we are studying an in vitro system using human samples to assess the role of primary complement component (C3a) in liver environment simulation.

Finally, lower levels of complement C3 in viral-induced ALF followed by a high frequency of C3a, C5a, and C5b/9 deposition in the dysfunctional liver parenchyma combined with higher HepG2 susceptibility suggest that therapies targeting the complement pathway should be further investigated to control liver regeneration/damage in fulminant hepatitis caused by viral hepatitis. Animal models should be the next very useful step to monitor ALF therapy since knockout studies using anticomplement antibodies, small interfering RNAs, and recombinant complement protein may be useful to evaluate the function of complements on cell proliferation and apoptosis.

\section{Data Availability}

The data used to support the findings of this study are included within the article.

\section{Conflicts of Interest}

All authors present no conflict of interests.

\section{Acknowledgments}

We would like to thank the study population from Hospital Federal de Bonsucesso and the physicians who contributed to this study. We are also thankful for the technical support from Fundação Oswaldo Cruz and Instituto Nacional do Câncer, especially to Andrea Henriques Pons from flow cytometry platform, as well as to Matheus A. Rajão and João Paulo de Biaso Viola from confocal microscopy platform. This work was supported by the Fundação de Amparo à Pesquisa do Estado do Rio de Janeiro (Grant \#6526/110.848/ 2013) and Brazilian National Council for Research and Development (Grant \#308951/2010-7).

\section{References}

[1] H. S. Lee, G. H. Choi, D. J. Joo et al., "Prognostic value of model for end-stage liver disease scores in patients with fulminant hepatic failure," Transplantation Proceedings, vol. 45, no. 8, pp. 2992-2994, 2013.

[2] W. M. Lee, "Acute liver failure," Seminars in Respiratory and Critical Care Medicine, vol. 33, no. 1, pp. 36-45, 2012.

[3] J. Wendon, J. Cordoba, A. Dhawan et al., "EASL clinical practical guidelines on the management of acute (fulminant) liver failure," Journal of Hepatology, vol. 66, no. 5, pp. 1047-1081, 2017.

[4] T. Whitehouse and J. Wendon, "Acute liver failure," Best Practice \& Research. Clinical Gastroenterology, vol. 27, no. 5, pp. 757-769, 2013.

[5] D. C. Santos, J. M. Martinho, L. F. Pacheco-Moreira et al., "Fulminant hepatitis failure in adults and children from a public hospital in Rio de Janeiro, Brazil," Brazilian Journal of Infectious Diseases, vol. 13, no. 5, pp. 323-329, 2009.

[6] S. Jayakumar, R. Chowdhury, C. Ye, and C. J. Karvellas, "Fulminant viral hepatitis," Critical Care Clinics, vol. 29, no. 3, pp. 677-697, 2013.

[7] J. G. Melgaço, F. M. Soriani, P. H. Sucupira et al., "Changes in cellular proliferation and plasma products are associated with liver failure," World Journal of Hepatology, vol. 8, no. 32, pp. 1370-1383, 2016.

[8] C. Brenner, L. Galluzzi, O. Kepp, and G. Kroemer, "Decoding cell death signals in liver inflammation," Journal of Hepatology, vol. 59, no. 3, pp. 583-594, 2013.

[9] S. Sun, Y. Guo, G. Zhao et al., "Complement and the alternative pathway play an important role in LPS/D-GalN-induced fulminant hepatic failure," PLoS One, vol. 6, no. 11, article e26838, 2011.

[10] Z. Wu, M. Han, T. Chen, W. Yan, and Q. Ning, "Acute liver failure: mechanisms of immune-mediated liver injury," Liver International, vol. 30, no. 6, pp. 782-794, 2010.

[11] D. Ricklin, G. Hajishengallis, K. Yang, and J. D. Lambris, "Complement: a key system for immune surveillance and homeostasis," Nature Immunology, vol. 11, no. 9, pp. 785797, 2010.

[12] M. M. Markiewski and J. D. Lambris, "The role of complement in inflammatory diseases from behind the scenes into the spotlight," The American Journal of Pathology, vol. 171, no. 3, pp. 715-727, 2007.

[13] P. F. Zipfel and C. Skerka, "Complement regulators and inhibitory proteins," Nature Reviews. Immunology, vol. 9, no. 10, pp. 729-740, 2009.

[14] J. Phieler, R. Garcia-Martin, J. D. Lambris, and T. Chavakis, "The role of the complement system in metabolic organs and metabolic diseases," Seminars in Immunology, vol. 25, no. 1, pp. 47-53, 2013.

[15] G. L. Xu, J. Chen, F. Yang, G. Q. Li, L. X. Zheng, and Y. Z. $\mathrm{Wu}$, " $\mathrm{C} 5 \mathrm{a} / \mathrm{C} 5 \mathrm{aR}$ pathway is essential for the pathogenesis of murine viral fulminant hepatitis by way of potentiating Fgl2/fibroleukin expression," Hepatology, vol. 60, no. 1, pp. 114-124, 2014.

[16] E. S. Reis, H. Chen, G. Sfyroera et al., "C5a receptordependent cell activation by physiological concentrations of desarginated C5a: insights from a novel label-free cellular assay," The Journal of Immunology, vol. 189, no. 10, pp. 4797-4805, 2012.

[17] C. Gaboriaud, N. M. Thielens, L. A. Gregory, V. Rossi, J. C. Fontecilla-Camps, and G. J. Arlaud, "Structure and activation of the C1 complex of complement: unraveling the puzzle," Trends in Immunology, vol. 25, no. 7, pp. 368-373, 2004. 
[18] J. S. Min, R. A. DeAngelis, E. S. Reis et al., "Systems analysis of the complement-induced priming phase of liver regeneration," The Journal of Immunology, vol. 197, no. 6, pp. 2500-2508, 2016.

[19] M. Song, Y. Sun, J. Tian et al., "Silencing retinoid X receptor alpha expression enhances early-stage hepatitis B virus infection in cell cultures," Journal of Virology, vol. 92, no. 8, 2018.

[20] R. Nakatake, M. Kaibori, Y. Nakamura et al., "Third-generation oncolytic herpes simplex virus inhibits the growth of liver tumors in mice," Cancer Science, vol. 109, no. 3, pp. 600-610, 2018.

[21] J. G. O'Grady, G. J. Alexander, K. M. Hayllar, and R. Williams, "Early indicators of prognosis in fulminant hepatic failure," Gastroenterology, vol. 97, no. 2, pp. 439-445, 1989.

[22] D. C. dos Santos, J. M. da Silva Gomes Martinho, L. F. Pacheco-Moreira et al., "Eosinophils involved in fulminant hepatic failure are associated with high interleukin-6 expression and absence of interleukin-5 in liver and peripheral blood," Liver International, vol. 29, no. 4, pp. 544-551, 2009.

[23] D. C. dos Santos, P. C. Neves, E. L. Azeredo et al., "Activated lymphocytes and high liver expression of IFN- $\gamma$ are associated with fulminant hepatic failure in patients," Liver International, vol. 32, no. 1, pp. 147-157, 2012.

[24] I. Jiménez, P. Aracena, M. E. Letelier, P. Navarro, and H. Speisky, "Chronic exposure of HepG2 cells to excess copper results in depletion of glutathione and induction of metallothionein," Toxicology In Vitro, vol. 16, no. 2, pp. 167-175, 2002.

[25] M. R. Flórez, M. Costas-Rodríguez, C. Grootaert, J. Van Camp, and F. Vanhaecke, " $\mathrm{Cu}$ isotope fractionation response to oxidative stress in a hepatic cell line studied using multicollector ICP-mass spectrometry," Analytical and Bioanalytical Chemistry, vol. 410, no. 9, pp. 2385-2394, 2018.

[26] K. Kowalczyk, A. Błauż, W. M. Ciszewski, A. Wieczorek, B. Rychlik, and D. Plażuk, "Colchicine metallocenyl bioconjugates showing high antiproliferative activities against cancer cell lines," Dalton Transactions, vol. 46, no. 48, pp. 1704117052, 2017.

[27] V. S. De Paula, L. Diniz-Mendes, L. M. Villar et al., "Hepatitis A virus in environmental water samples from the Amazon Basin," Water Research, vol. 41, no. 6, pp. 1169-1176, 2007.

[28] S. D. Pas and H. G. Niesters, "Detection of HBV DNA using real time analysis," Journal of Clinical Virology, vol. 25, no. 1, pp. 93-94, 2002.

[29] E. Yurtcu, O. D. Iseri, and F. I. Sahin, "Effects of ascorbic acid and $\beta$-carotene on HepG2 human hepatocellular carcinoma cell line," Molecular Biology Reports, vol. 38, no. 7, pp. 42654272, 2011.

[30] R. C. Duhamel and D. A. Johnson, "Use of nonfat dry milk to block nonspecific nuclear and membrane staining by avidin conjugates," The Journal of Histochemistry \& Cytochemistry, vol. 33, no. 7, pp. 711-714, 1985.

[31] C. G. Antoniades, P. A. Berry, J. A. Wendon, and D. Vergani, "The importance of immune dysfunction in determining outcome in acute liver failure," Journal of Hepatology, vol. 49, no. 5, pp. 845-861, 2008.

[32] X. Qin and B. Gao, "The complement system in liver diseases," Cellular \& Molecular Immunology, vol. 3, no. 5, pp. 333-340, 2006.

[33] H. S. Shin, S. P. Kim, S. H. Han et al., "Prognostic indicators for acute liver failure development and mortality in patients with hepatitis a: consecutive case analysis," Yonsei Medical Journal, vol. 55, no. 4, pp. 953-959, 2014.

[34] H. Lin, Q. Zhang, X. Li, Y. Wu, Y. Liu, and Y. Hu, "Identification of key candidate genes and pathways in hepatitis B virusassociated acute liver failure by bioinformatical analysis," Medicine, vol. 97, no. 5, article e9687, 2018.

[35] M. L. Chang, C. J. Kuo, H. C. Huang, Y. Y. Chu, and C. T. Chiu, "Association between leptin and complement in hepatitis C patients with viral clearance: homeostasis of metabolism and immunity," PLoS One, vol. 11, no. 11, article e0166712, 2016.

[36] J. J. Zhang, Y. C. Fan, Z. H. Zhang et al., "Methylation of suppressor of cytokine signalling 1 gene promoter is associated with acute-on-chronic hepatitis B liver failure," Journal of Viral Hepatitis, vol. 22, no. 3, pp. 307-317, 2014.

[37] A. El-Shamy, A. D. Branch, T. D. Schiano, and P. D. Gorevic, "The complement system and $\mathrm{Clq}$ in chronic hepatitis $\mathrm{C}$ virus infection and mixed cryoglobulinemia," Frontiers in Immunology, vol. 9, p. 1001, 2018.

[38] M. J. Rutkowski, M. E. Sughrue, A. J. Kane, B. J. Ahn, S. Fang, and A. T. Parsa, "The complement cascade as a mediator of tissue growth and regeneration," Inflammation Research, vol. 59, no. 11, pp. 897-905, 2010.

[39] P. E. Marques, S. S. Amaral, D. A. Pires et al., "Chemokines and mitochondrial products activate neutrophils to amplify organ injury during mouse acute liver failure," Hepatology, vol. 56, no. 5, pp. 1971-1982, 2012.

[40] J. M. Stapp, V. Sjoelund, H. A. Lassiter, R. C. Feldhoff, and P. W. Feldhoff, "Recombinant rat IL-1beta and IL-6 synergistically enhance $\mathrm{C} 3 \mathrm{mRNA}$ levels and complement component C3 secretion by H-35 rat hepatoma cells," Cytokine, vol. 30, no. 2, pp. 78-85, 2005.

[41] M. Daveau, M. Benard, M. Scotte et al., "Expression of a functional $\mathrm{C} 5 \mathrm{a}$ receptor in regenerating hepatocytes and its involvement in a proliferative signaling pathway in rat," Journal of Immunology, vol. 173, no. 5, pp. 3418-3424, 2004.

[42] M. D. Leise, J. J. Poterucha, and J. A. Talwalkar, "Druginduced liver injury," Mayo Clinic Proceedings, vol. 89, no. 1, pp. 95-106, 2014.

[43] S. S. Rensen, Y. Slaats, A. Driessen et al., "Activation of the complement system in human nonalcoholic fatty liver disease," Hepatology, vol. 50, no. 6, pp. 1809-1817, 2009.

[44] F. T. Ozer, A. Barut, A. Inal, and A. Hacibektaşoğlu, "Complement C3 and C4 levels in serum from acute viral hepatitis," Mikrobiyoloji Bülteni, vol. 26, no. 4, pp. 314-319, 1992.

[45] B. N. Pham, J. F. Mosnier, F. Durand et al., "Immunostaining for membrane attack complex of complement is related to cell necrosis in fulminant and acute hepatitis," Gastroenterology, vol. 108, no. 2, pp. 495-504, 1995.

[46] A. K. Chauhan and T. L. Moore, "Presence of plasma complement regulatory proteins clusterin (Apo J) and vitronectin (S40) on circulating immune complexes (CIC)," Clinical and Experimental Immunology, vol. 145, no. 3, pp. 398-406, 2006.

[47] D. Wieland, M. Hofmann, and R. Thimme, "Overcoming CD8 + T-cell exhaustion in viral hepatitis: lessons from the mouse model and clinical perspectives," Digestive Diseases, vol. 35, no. 4, pp. 334-338, 2017.

[48] J. A. Cienfuegos, F. Rotellar, J. Baixauli, F. Martínez-Regueira, F. Pardo, and J. L. Hernández-Lizoáin, "Liver regeneration-the best kept secret. A model of tissue injury response," Revista 
Española de Enfermedades Digestivas, vol. 106, no. 3, pp. 171194, 2014.

[49] R. R. Buchner, T. E. Hugli, J. A. Ember, and E. L. Morgan, "Expression of functional receptors for human C5a anaphylatoxin (CD88) on the human hepatocellular carcinoma cell line HepG2. Stimulation of acute-phase protein-specific mRNA and protein synthesis by human C5a anaphylatoxin," The Journal of Immunology, vol. 155, no. 1, pp. 308-315, 1995.

[50] E. Güven, K. Duus, M. C. Lydolph, C. S. Jørgensen, I. Laursen, and G. Houen, "Non-specific binding in solid phase immunoassays for autoantibodies correlates with inflammation markers," Journal of Immunological Methods, vol. 403, no. 1-2, pp. 26-36, 2014.

[51] A. Samuelson, M. Glimåker, E. Skoog, J. Cello, and M. Forsgren, "Diagnosis of enteroviral meningitis with IgG-EIA using heat-treated virions and synthetic peptides as antigens," Journal of Medical Virology, vol. 40, no. 4, pp. 271-277, 1993.

[52] M. A. Moore, Z. W. Hakki, R. L. Gregory, L. E. Gfell, W. K. Kim-Park, and M. J. Kowolik, "Influence of heat inactivation of human serum on the opsonization of Streptococcus mutans," Annals of the New York Academy of Sciences, vol. 832, no. 1, pp. 383-393, 1997.

[53] R. D. Soltis, D. Hasz, M. J. Morris, and I. D. Wilson, "The effect of heat inactivation of serum on aggregation of immunoglobulins," Immunology, vol. 36, no. 1, pp. 37-45, 1979.

[54] S. M. Fouraschen, Q. Pan, P. E. de Ruiter et al., "Secreted factors of human liver-derived mesenchymal stem cells promote liver regeneration early after partial hepatectomy," Stem Cells and Development, vol. 21, no. 13, pp. 2410-2419, 2012.

[55] H. Bantel and K. Schulze-Osthoff, "Mechanisms of cell death in acute liver failure," Frontiers in Physiology, vol. 3, p. 79, 2012.

[56] M. Maes, M. Vinken, and H. Jaeschke, "Experimental models of hepatotoxicity related to acute liver failure," Toxicology and Applied Pharmacology, vol. 290, pp. 86-97, 2016.

[57] R. Saich, C. Selden, M. Rees, and H. Hodgson, "Characterization of pro-apoptotic effect of liver failure plasma on primary human hepatocytes and its modulation by molecular adsorbent recirculation system therapy," Artificial Organs, vol. 31, no. 9, pp. 732-742, 2007.

[58] W. B. Du, X. P. Pan, X. P. Yu et al., "Effects of plasma from patients with acute on chronic liver failure on function of cytochrome P450 in immortalized human hepatocytes," Hepatobiliary \& Pancreatic Diseases International, vol. 9, no. 6, pp. 611-614, 2010.

[59] D. A. Peterson, L. G. Wolfe, E. P. Larkin, and F. W. Deinhardt, "Thermal treatment and infectivity of hepatitis A virus in human feces," Journal of Medical Virology, vol. 2, no. 3, pp. 201-206, 1978.

[60] H. Nishitsuji, K. Harada, S. Ujino et al., "Investigating the hepatitis B virus life cycle using engineered reporter hepatitis B viruses," Cancer Science, vol. 109, no. 1, pp. 241-249, 2018.

[61] P. Gripon, S. Rumin, S. Urban et al., "Infection of a human hepatoma cell line by hepatitis B virus," Proceedings of the National Academy of Sciences of the United States of America, vol. 99, no. 24, pp. 15655-15660, 2002.

[62] A. M. Gaspar, C. L. Vitral, C. F. Yoshida, and H. G. Schatzmayr, "Primary isolation of a Brazilian strain of hepatitis A virus (HAF-203) and growth in a primate cell line (FRhK-
4)," Brazilian Journal of Medical and Biological Research, vol. 25, no. 7, pp. 697-705, 1992.

[63] R. C. Zangar, N. Bollinger, T. J. Weber, R. M. Tan, L. M. Markillie, and N. J. Karin, "Reactive oxygen species alter autocrine and paracrine signaling," Free Radical Biology \& Medicine, vol. 51, no. 11, pp. 2041-2047, 2011.

[64] S. Sarwar, A. A. Khan, A. Alam et al., "Predictors of fatal outcome in fulminant hepatic failure," Journal of the College of Physicians and Surgeons-Pakistan, vol. 16, no. 2, pp. 112-116, 2006.

[65] M. McMillin, G. Frampton, S. Grant et al., "Bile acid-mediated sphingosine-1-phosphate receptor 2 signaling promotes neuroinflammation during hepatic encephalopathy in mice," Frontiers in Cellular Neuroscience, vol. 11, p. 191, 2017.

[66] G. S. Herbert, K. B. Prussing, A. L. Simpson et al., "Early trends in serum phosphate and creatinine levels are associated with mortality following major hepatectomy," $H P B$, vol. 17, no. 12, pp. 1058-1065, 2015. 


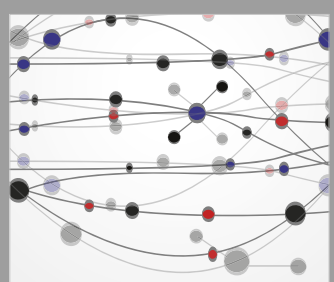

The Scientific World Journal
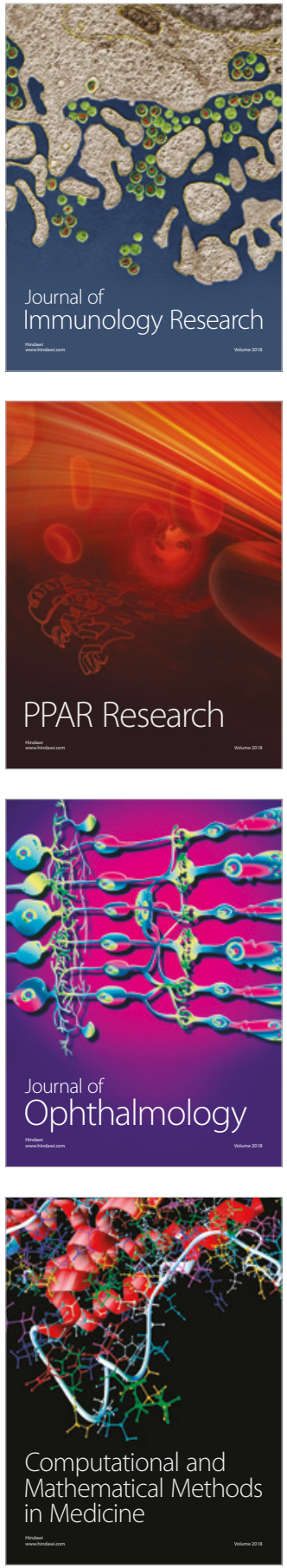

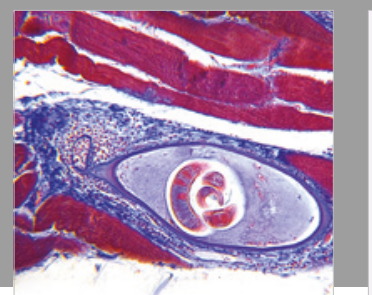

Gastroenterology Research and Practice

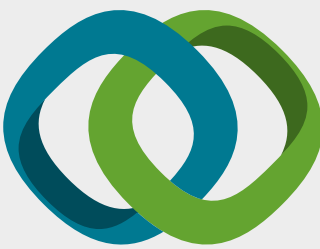

\section{Hindawi}

Submit your manuscripts at

www.hindawi.com
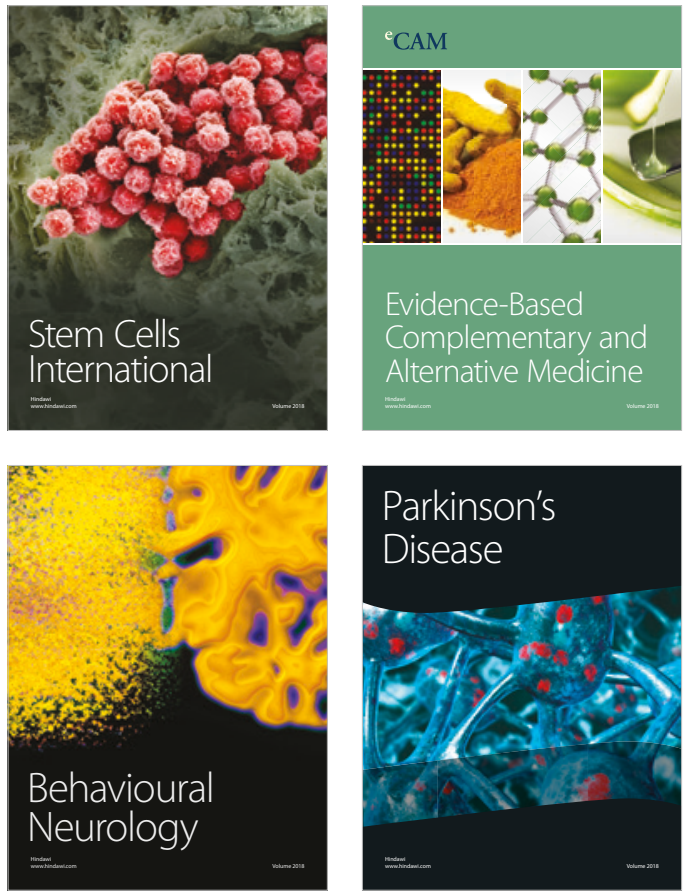

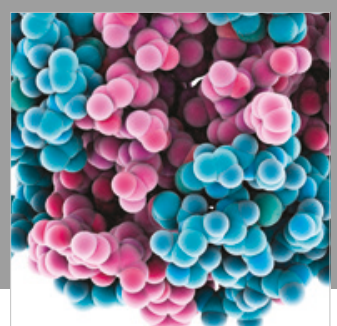

ournal of

Diabetes Research

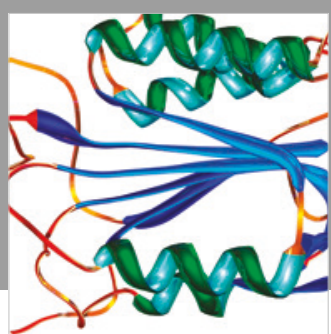

Disease Markers
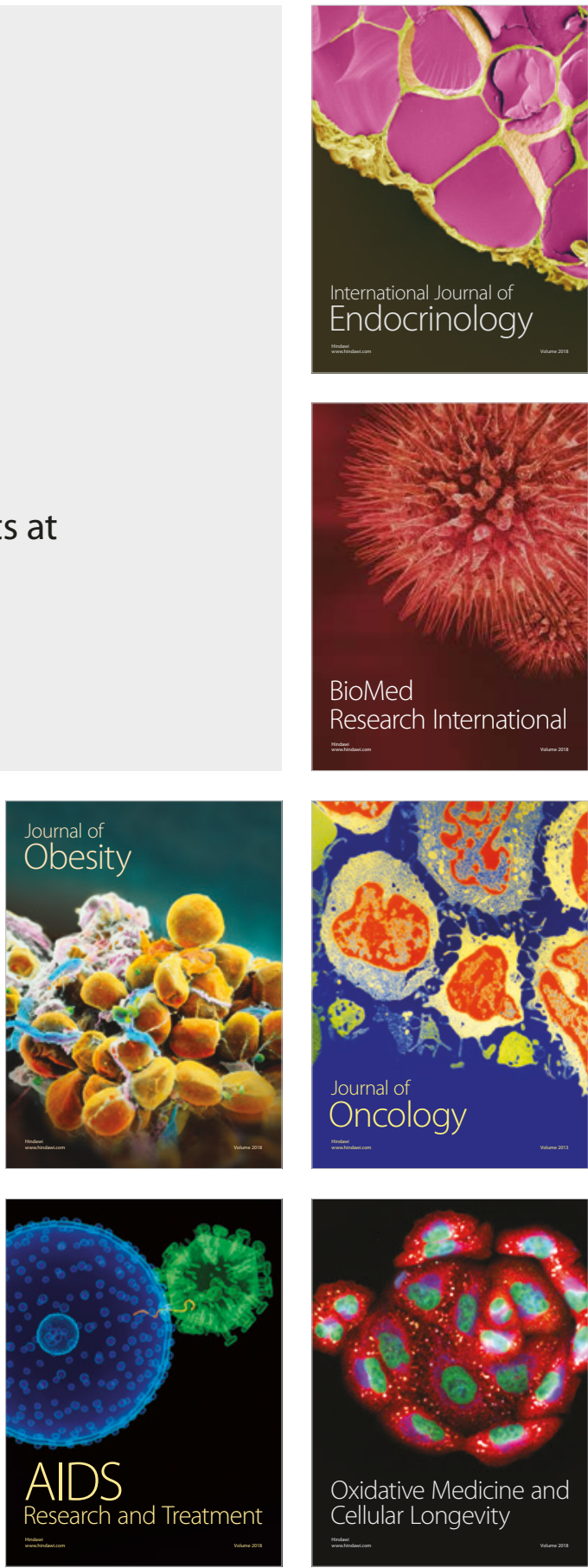